\title{
Antropofagia e Tropicalismo: identidade cultural?
}

\section{Resumo}

Este artigo pretende analisar a retomada do ideário modernista pela arte de vanguarda dos anos sessenta. O Manifesto Antropófago (1928) de Oswald de Andrade (1890-1954) passa a fazer parte da estratégia dos artistas e intelectuais da vanguarda artística na busca do estabelecimento de uma especificidade cultural para o Brasil. A dificuldade em estabelecer uma identidade para as práticas artístico-culturais do país, refere-se à própria ambiguidade da nação brasileira com sua herança européia e fortemente influenciada pelas culturas indígena e negra.

Palavras-chave:

Tropicalismo, antropofagia, cultura brasileira 


\title{
Anthropophagy and Tropicalism: cultural identity?
}

\author{
JHANAINNA SILVA PEREIRA JEZZINI
}

\begin{abstract}
This article analyzes the resumption of modernist ideals by avant-garde art of the sixties. The Manifesto Antropófago (1928) by Oswald de Andrade (1890-1954) becomes part of the strategy of artists and intellectuals of the artistic vanguard in seeking the establishment of a cultural uniqueness to the country. The difficulty of establishing an identity for artistic and cultural practices of the country, it refers to the very ambiguity of the Brazilian nation with its European heritage, strongly influenced by indigenous and black cultures.
\end{abstract}


0 conceito de Antropofagia de Oswald de Andrade (18901954) adquire um sentido mais radical com a chamada geração tropicalista. Herdeiros do Concretismo e do Neoconcretismo estes artistas, segundo Hélio Oiticica (1937-1980), efetivaram a transformação no modo de ver e sentir a arte propondo novas estruturas que possibilitassem uma “posição crítica realmente universal, profundamente revolucionária, ao campo das artes, do conhecimento, do comportamento" (OITICICA, 1968a).

Quando Hélio Oiticica refere-se aos dois momentos construtivos da arte brasileira, Concretismo e Neoconcretismo, não os vê como tendências ou estilos restritos a um determinado espaço e tempo, a exemplo do que acontece nos movimentos artísticos tradicionais (Cubismo, Futurismo etc.). O projeto construtivo brasileiro aponta, segundo Oiticica (1968a), para uma universalidade crítica e criativa. Tal universalidade consiste, entre outros fatores, na tentativa de contestação da repressão cultural que se dava no país, revelando-se em uma prática artística que não separa linguagem experimental e crítica cultural, projeto de criação e projeto de atuação, convergindo ao mesmo tempo ao comprometimento e à renovação artística. Esta repressão não diz respeito apenas ao regime político ditatorial vigente na época, mas também ao "colonialismo cultural" imposto pelos países hegemônicos e reforçado no período da Guerra Fria.

O sentido de criação de uma linguagem universal para a arte brasileira compreende a absorção das manifestações artísticas do país e daquelas ocorridas no estrangeiro. A inserção da linguagem artística em um contexto universal implica, para Oiticica, na desalienação e na não fragmentação dos problemas locais, ou seja, na superação da "condição provinciana estagnatória”, por meio da deglutição dos "valores positivos dados por essa condição" (OITICICA, 
1970, p. 44) e desemboca em um projeto de caracterização cultural que recusa qualquer espécie de colonialismo.

O posicionamento crítico universal unido ao experimentalismo da arte de vanguarda estabelece um elemento construtivo que, segundo Hélio Oiticica, indica um modo de admitir a falta de caráter da formação cultural brasileira. Tomar uma posição crítica universal é "estar apto a julgar, julgar-se, optar, criar [...], assumir e deglutir a superficialidade e a mobilidade dessa cultura" (OITICICA, 1970, p. 44). É em Tropicália que Oiticica incorpora essas duas questões, experimentalismo e crítica, propondo "a transformação radical no campo dos conceitos-valores vigentes” (OITICICA, 1970, p. 45).

O caráter revolucionário desta universalidade diz respeito às expressões de inconformismo social, exemplificadas nas posições dos Centros Populares de Cultura (CPCs) e no processo de renovação musical do Grupo Baiano - formado por Caetano Veloso, Gilberto Gil, Torquato Neto, Capinam, Os Mutantes e Tom Zé - com sua potencialidade crítica na luta contra a repressão. Essas manifestações de caráter revolucionário não se limitam a questões esteticistas, pois "tudo o que revoluciona o faz de modo geral” (OITICICA, 1968a). O caráter revolucionário que Hélio Oiticica atribui às criações do Tropicalismo, não distingui, segundo Celso Favaretto (2000, p. 146), "experimentalismo e crítica da cultura" e ainda não privilegia "posições discrepantes, quando se trata de "constatar um estado geral cultural”. Essa posição revolucionária evidencia a atualização das linguagens artísticas e pode ser resumida na experimentalidade e na construtividade.

Foram as formulações teóricas do Grupo Neoconcreto, do Cinema Novo, da poesia e do teatro engajados, somadas às diretrizes colocadas no texto do "Esquema Geral da Nova Objetividade" e à montagem de Tropicália, essas duas últimas realizadas por Hélio Oiticica, que culminaram no Tropicalismo. Este momento cultural brasileiro é muito bem representado nas experiências musicais de Caetano Veloso e de Gilberto Gil; no teatro de José Celso Martinez Corrêa com a encenação de O Rei da Vela de Oswald de Andrade; no cinema de Glauber Rocha (1939-1981) com Terra em Transe; nos projetos gráficos de Rogério Duarte. O Tropicalismo foi um período em que todas as modalidades das artes de vanguarda do país (cinema, teatro, artes plásticas e música) buscavam estabelecer um fenômeno cultural que fosse dotado de sentido político, social e ético. Oiticica não entende o Tropicalismo, assim como os projetos construtivos da arte brasileira, como um movimen- 
to histórico a mais, um "ismo", mas sim, como a síntese do debate, da criação e da crítica artística que vinha ocorrendo no país desde o final da década de cinquenta e que objetivava uma ruptura de uma linguagem artística convencional e dava espaço à experimentação e à preocupação construtiva.

Hélio Oiticica lança o termo "Tropicália” para nomear o ambiente que expôs pela primeira vez no Museu de Arte Moderna do Rio de Janeiro na mostra "Nova Objetividade Brasileira" em 1967. No mesmo ano, por sugestão do cineasta Luiz Carlos Barreto, a expressão também passa a designar uma nova música de Caetano Veloso. Além do trabalho ambiental e da canção, a palavra Tropicália instituiu um "projeto cultural coletivo" (BASUALDO, 2007, p. 19) que, mesmo sobrevivendo a um curto período de tempo, pouco mais de um ano, formulou uma das fases mais agitadas da cultura brasileira.

\section{O projeto construtivo brasileiro}

As contribuições do Concretismo e do Neoconcretismo foram significativas tanto para a formulação de Tropicália (manifestação ambiental de Oiticica), quanto para a proposta da Nova Objetividade. Mesmo negando a racionalidade do Concretismo, as invenções dos artistas do Grupo Neoconcreto, de maneira geral, decorrem daquele movimento. Por este motivo, Ferreira Gullar sugere o nome Neoconcretismo, neologismo que passa a designar as novas realizações dos artistas da vanguarda carioca que se mostravam "tão diferente(s) do que se entendia por arte concreta que não tinha mais cabimento continuarmos a adotar tal denominação" (GULLAR, 2007, p. 41). Segundo o Manifesto Neoconcreto ${ }^{1}$ (1959) o racionalismo substituía a autonomia artística pelas noções científicas; para os neoconcretos, as dimensões artísticas (forma, espaço, tempo, estrutura) deveriam, antes de serem racionalizadas, ligarem-se à significação existencial e emotiva.

Na análise de Ronaldo Brito (1999, p. 35), foi diante da prática e do entendimento dos conceitos construtivos que a arte brasileira passou a lidar, efetivamente, com as implicações resultantes da arte moderna: a "ruptura do espaço organizado a partir da perspectiva" e a indagação "da relação quadro/realidade". A entrada das ideologias das vertentes construtivas no Brasil é verificada, ainda segundo Brito, desde a década de trinta com a fundação da arquitetura moderna e influenciou a produção artística até as manifestações neoconcretas da década de sessenta. 
Inicialmente o Concretismo brasileiro tomaria sua especificidade diante da não submissão a conteúdos ideológicos e da "objetividade de seu modo de produção" (BRITO, 1999, p. 36). A entrada da tradição construtiva nos projetos da vanguarda brasileira ganhou impulso com a premiação do trabalho de Max Bill (1908-1994) - Unidade Tripartida (1947-8) - na I Bienal de São Paulo (1951). Esta obra configura, segundo o próprio artista, "o espaço infinito em seu movimento infinito" (BILL, apud GULLAR, 1999, p. 222), estabelecendo, assim, um problema matemático exemplificado pela Fita de Moebius que revela a continuidade de uma superfície.

Em 1952, ante os princípios racionalistas da arte concreta de Max Bill - que, entre outros aspectos, admitiam: os processos matemáticos na produção artística; o afastamento de qualquer conotação lírica ou simbólica no trabalho de arte; a exploração dos efeitos ópticos; e a valorização da ideologia da sociedade industrial sem interferência da subjetividade forma-se em São Paulo o Grupo Ruptura com artistas como Waldemar Cordeiro (1925-1973), Geraldo de Barros (19231998), Luís Sacilotto (1924-2003), Lothar Charoux (1912-1987), Maurício Nogueira Lima (1930-1999), entre outros. Em seu manifesto a inauguração de um novo modo de fazer arte era enfatizada pela "intuição artística dotada de princípios claros e inteligentes, e de grandes possibilidades de desenvolvimento prático" (CORDEIRO (et al.), 1952, p. 105). "Optar pela arte concreta no início dos anos 50 significava optar por uma estratégia cultural universalista e evolucionista" (BRITO, 1999, p. 39), no sentido de calcar verdadeiras bases à pesquisa artística do país. A inserção do racionalismo de noções científicas nas práticas da vanguarda é justificada na busca da transformação da percepção convencional do espectador. Essa ruptura da percepção convencional se daria, nas práticas concretas, através da oposição às formas artísticas dominantes: figura e fundo; perspectiva; e representação do real. No caso brasileiro, a prática construtiva com sua recolocação da percepção, diz respeito também ao desejo de superação do subdesenvolvimento decorrido do atraso tecnológico.

Do interior do Concretismo nasce o Neoconcretismo, e com ele o seu manifesto, onde se lê: "O neoconcreto [...] nega a validez das atitudes cientificistas e positivistas em arte e repõe o problema da expressão", e mais adiante "a arte neoconcreta funda um novo espaço expressivo”. É este novo espaço expressivo que estabelece a crise da representação no plano bidimensional e propõe a participação do espectador. 
As proposições neoconcretas passaram a representar uma reinterpretação não somente do Concretismo, mas também de outras correntes históricas ocidentais amparadas na lógica da razão, a exemplo do Neoplasticismo de Piet Mondrian e do Construtivismo russo. Os neoconcretos reconhecem em Mondrian (1872-1944) a diluição da superfície e a origem da construção de um novo espaço; e em Maliévitch (1878-1935) a "transcendência do racional e do sensorial" (GULLAR, 1959b). Para o Grupo Neoconcreto, a revisão alargada das ideias de Mondrian e de Maliévitch possibilitava retirar da arte a condição de "mera ilustração de conceitos apriorísticos" (GULLAR, 1999, p. 245). Nas produções neoconcretas, os artistas mesclavam tal revisão das correntes construtivas com a "experiência direta da percepção" transcendendo, assim, "a simples materialidade do objeto" (FAVARETTO, 200o, p. 40).

Enquanto Mondrian contribui para as novas experiências com sua harmonia plástica universal, obtida na nova concepção de espaço e no equilíbrio entre as dimensões artísticas, em especial a cor e a forma, Maliévitch o faz por meio da inserção da sensibilidade no trabalho artístico, levando a arte para além de uma representação pictórica e conferindo-lhe organicidade. Para os neoconcretos, o trabalho artístico adquire tal organicidade unindo o seu deslocamento para o espaço real com a inserção da participação e da sensibilidade, é isso também que resulta no novo espaço neoconcreto que, por sua vez, seria um espaço ativo. Ativo porque adquire a noção de acontecimento devido a inclusão do tempo (duração) no trabalho.

Para Ferreira Gullar (1999, p. 240), a estrutura geométrica da arte concreta agrava o problema da representação, pois, ao contrário do que ocorre com as formas abstratas de Mondrian e Maliévitch que se mostram dotadas de expressividade, o geometrismo concreto brasileiro diz respeito apenas à forma como matéria. O Neoconcretismo reage exatamente ante "o conceito puramente visual da forma" (GULLAR, 1999, p. 240) e nessa manifestação reside sua crítica mais aguda às formulas adotadas pelos artistas concretos.

O texto "Inter relação das artes" (1961) discute a necessidade de retomar o caráter universal da expressão plástica de Mondrian (horizontalidade e verticalidade, e o uso das cores primárias), sugerindo que o artista abdique da expressão de "sentimentos individuais (pessoais)" (OITICICA, 1961); fato que não implica o abandono da intuição. Segundo Oiticica, os artistas erraram ao empregar a universalidade mondrianesca de modo automático e formalista; assim, "o que era univer- 
sal voltou a se mostrar novamente relativo" (OITICICA, 1961). A expansão das ideias de Mondrian permite que a produção neoconcreta ganhe, além da universalidade, organicidade e espontaneidade. Oiticica atribui à experiência construtiva neoconcreta de Lygia Clark uma importância universal, pois seu trabalho além de novo, adquire um caráter orgânico, apresentando-se como a "retomada de força interior e de espontaneidade perdida" (OITICICA, 1961).

O surgimento do Concretismo na cena cultural brasileira sinaliza a amizade intelectual entre Hélio Oiticica e os irmãos Haroldo de Campos (1929-2003) e Augusto de Campos. As suas preocupações estéticas convergiam para um objetivo: formular uma linguagem autêntica para a arte do país. Mesmo que no início do Neoconcretismo estivessem aparentemente em grupos opostos - enquanto os poetas avançavam a composição da poesia para uma fase matemática, Hélio Oiticica inseria a dimensão do sensível no trabalho artístico - eles encontram uma "materialidade" que altera "as relações da cor e da palavra com a forma" (AGUILAR, 2008, p. 239). Em 1955, Haroldo de Campos publica no Diário de São Paulo e no Correio da Manhã no Rio de Janeiro o artigo "A obra de arte aberta", antecipando em algumas questões a "Obra aberta" de Umberto Eco, o que, segundo o próprio Haroldo (1987, p. 218), é reconhecido pelo filósofo italiano. No artigo, Campos elucida a "provisoriedade do estético" que se dava na arte contemporânea. Para o poeta (1987, p. 218), Hélio Oiticica insere suas atividades artísticas neste contexto, "um contexto marcado pela ideia da provisoriedade, de fragilidade do estético" (CAMPOS, 1987, p. 218). "Uma das características fundamentais da arte contemporânea [...] é a da provisoriedade do estético. [...] a arte contemporânea [...] parece ter incorporado o relativo e o transitório como dimensão mesma de seu ser" (CAMPOS, 1972, p. 15), na produção artística internacional essa provisoriedade é conferida, por exemplo, nas obras de Kurt Schwitters (18871948). Celso Favaretto (2000, p. 173) refere-se ao Parangolé de Hélio Oiticica como versão brasileira desta problematização, que explorando "a provisoriedade do estético, ressignifica a criação coletiva, a marginalidade do artista e o político da arte".

\section{Origens da nova objetividade}

Uma das características comum entre o Neoconcretismo e a Nova Objetividade pode ser encontrada na preocupação em relacionar as pesquisas estéticas com a tentativa de caracterização da cultura brasileira. Além disso, o movimento neocon- 
creto realizou uma série de rupturas de grande importância para a arte de vanguarda do país, representada por Hélio Oiticica, Lygia Clark, Lygia Pape, Waldemar Cordeiro, Antonio Dias, Rubens Gerchman (1942-2008), Carlos Vergara, Glauco Rodrigues (1929-2004), Sérgio Ferro, Flávio Império (19351985), Nelson Leirner e Marcello Nitsche. Tais rupturas buscavam, entre outras características, a superação dos suportes tradicionais (quadro, escultura etc.) por meio da realização direta do trabalho no espaço, o que deu início às estruturas espaciais nas práticas neoconcretas; e que em pouco tempo originaria as proposições ambientais de Hélio Oiticica, a exemplo de Tropicália.

As estruturas espaciais neoconcretas não são meras esculturas a serem contempladas passivamente, são estruturas a serem vivenciadas no espaço e no tempo. Diante disso, Hélio Oiticica formula a concepção de "desenvolvimento nuclear da cor" (OITICICA, 1986, p. 40), que em suas obras pode ser verificada nos Bilaterais, nos Relevos Espaciais, nos Núcleos e nos Penetráveis.

Ao publicar o texto "Esquema Geral da Nova Objetividade" (1967), no catálogo que acompanhava a exposição "Nova Objetividade Brasileira", Hélio Oiticica propõe seis itens para estabelecer "um estado típico da arte brasileira de vanguarda” (OITICICA, 1967b, p. 154): “1. vontade construtiva geral; 2. tendência para o objeto ao ser negado e superado o quadro de cavalete; 3. participação do espectador (corporal, tátil, visual, semântica, etc.); 4. abordagem e tomada de posição em relação a problemas políticos, sociais e éticos; 5 . tendência para proposições coletivas e consequente abolição dos 'ismos' característicos da primeira metade do século na arte de hoje (tendência esta que pode ser englobada no conceito de 'arte pós-moderna' de Mário Pedrosa²); 6. ressurgimento e novas formulações do conceito de antiarte" (OITICICA, 1967b, p. 154). Neste conjunto de ações são enfatizados dois aspectos para que se dê a especificidade da arte brasileira de vanguarda: o experimentalismo e o engajamento. É por meio destes aspectos fundamentais que a Nova Objetividade concentra a busca para uma nova expressão na arte do país.

A "vontade construtiva geral" pode ser considerada, nas palavras do artista, como uma etapa amadurecida do ideário antropofágico de Oswald de Andrade; dela nascem a arquitetura nacional, o Concretismo e o Neoconcretismo que, mesmo sendo inovadores, não deixam de remeter ao Movimento de 22 no seu repúdio ao "colonialismo cultural". Hélio Oiticica argumenta, no primeiro item do "Esquema Geral", que 
na maneira peculiar que o brasileiro apreende as influências internacionais já está explícita essa vontade construtiva resultante da "redução imediata de todas as influências externas a modelos nacionais" (OITICICA, 1967b, p. 155) e que se traduz no desejo de formação cultural. No texto, Oiticica traça uma linhagem preocupada antes com a caracterização de uma atitude brasileira de vanguarda, do que com o estabelecimento de características plástico-formais típicas de nossa arte. Essa atitude brasileira diria respeito à procura de uma especificidade cultural ligada diretamente ao subdesenvolvimento social.

Desde sua adesão ao Concretismo, Hélio Oiticica manifesta a necessidade de procurar uma especificidade brasileira na linguagem artística; aliando-se com outros artistas, não poupa esforços para formular uma linguagem autêntica para a arte do país. Essa procura pela autenticidade da arte brasileira faria parte de todo o projeto construtivo, Concretismo e Neoconcretismo. É importante esclarecer que a contribuição do Neoconcretismo para a formulação de um estado típico da arte brasileira de vanguarda não é somente formal, mas principalmente metodológica; pois, foi neste período que se deu uma valorização do processo experimental na arte do país, fazendo com que artistas como Hélio Oiticica, Lygia Clark (1920-1988) e Lygia Pape (1927-2004) transcendessem questões formais do Concretismo e posteriormente também do Neoconcretismo.

As formulações das vanguardas artísticas ocorridas desde a década de cinquenta propõem uma atitude antropofágica para o estabelecimento de uma cultura brasileira. A Antropofagia, tal como proposta por Oswald de Andrade, seria uma forma de romper com os modelos de dependência cultural, assim como, a afirmação de uma consciência emancipada da cultura brasileira. Já no Manifesto da Poesia Pau Brasil de 1924, Oswald expressa o desejo de fazer do Brasil uma "cultura de exportação", à semelhança do que havia se dado com o produto (madeira) pau-Brasil, colocava a possibilidade de sua poesia ser um produto cultural que, antes de nada dever à cultura européia, pudesse vir a influenciá-la, gerando, assim, uma cultura apta à exportação, portanto, inserida no mercado internacional. A continuidade desta ideia seria dada, por Oswald de Andrade, no Manifesto Antropófago. Quando Haroldo e Augusto de Campos e Décio Pignatari redigem, em 1958, o "Plano-piloto para a poesia concreta" retomam a ideia da Antropofagia e de uma "cultura de exportação", antecipando o projeto do Tropicalismo e da Nova Objetividade. A proposta do "Plano-piloto" consiste na assimilação da produção 
das vanguardas européias; na desconstrução da lógica espacial e visual; e na criação do poema-objeto. Os apontamentos feitos pelos poetas concretos formadores do Grupo Noigandres $^{3}$, provocaram o debate das questões da vanguarda dado ao longo de toda a década de sessenta.

Para Haroldo de Campos (1987, p. 219), a Antropofagia indica os "fenômenos de desconstrução, de destruição de padrões, de esquemas". Em "A poesia concreta e a realidade nacional" (CAMPOS, 1962, pp. 28-31), o poeta refere-se à Antropofagia como uma "devoração crítica" fundamental para compreender e superar o subdesenvolvimento do país, acreditando que Oswald de Andrade já havia pensado em uma "poesia de exportação" quando a prática poética era predominantemente parnasiana. A apreensão do Manifesto Antropófago, escrito por Oswald de Andrade em 1928, se dava na poesia concreta através da deglutição: do Futurismo importado da Europa; da "linguagem surrealista" do povo primitivo; da ingenuidade das primeiras crônicas brasileiras; e até mesmo da "fala cotidiana e coloquial".

A importância da Antropofagia para Hélio Oiticica não se limitaria ao Tropicalismo e à proposta da Nova Objetividade. O Manifesto Antropófago foi de tal maneira significativo para o artista que redige em 1972, morando nos Estados Unidos, uma tradução em inglês do texto de Oswald de Andrade. Mas, foi na década de sessenta que, diante da inspiração antropofágica, o Tropicalismo desejou "inscrever a cultura brasileira em um horizonte de internacionalismo que se manifestaria, no fim das contas, em um ato de intervenção interpretativa destinado a repensá-la - e reformulá-la - em sua totalidade" (BASUALDO, 2007, p. 25).

Inscrever a cultura em um horizonte internacional implica na exportação de ideias, como também, na existência de singularidades. Um caráter internacional, quando impregnado a uma determinada cultura, relaciona-se ativa e dialeticamente com outras culturas, sem que exista uma sentença absoluta a ser adotada como lei, "a Nova Objetividade sendo, pois, um estado típico da arte brasileira atual, o é também no plano internacional, [...] uma 'chegada', constituída de múltiplas tendências onde a 'falta de unidade de pensamento' é uma característica importante" (OITICICA, 1967b, pp. 154-155). Para Ferreira Gullar (2002, p. 53), a internacionalização da arte seria "a tendência para um estilo ou um vocabulário comum aos artistas de todos os países - é naturalmente uma consequência da internacionalização da vida contemporânea". 
Mesmo que com o "Esquema Geral", Hélio Oiticica tente redefinir o discurso que acompanhava a arte de vanguarda, em momento algum ele rompe ou nega sua trajetória anterior. $\mathrm{O}$ que Oiticica faz é repropor o debate artístico através do desenvolvimento de seu próprio trabalho. Foi a consolidação das poéticas construtivas somadas à "chegada" ao objeto e à participação do espectador que possibilitaram a proposição de um estado típico para a arte da vanguarda brasileira. Com a proposta da Nova Objetividade, Hélio Oiticica identifica "o conjunto das variadas experiências de vanguarda que vinham se apresentando em uma série de exposições" (FAVARETTO, 2007, p. 9o). Segundo Celso Favaretto (2007, p. 90), a Nova Objetividade foi uma espécie de "balanço das correntes de vanguarda e o resultado de propostas e discussões que vinham se desenvolvendo, principalmente depois do golpe de 1964".

O Tropicalismo uniu esse discurso da arte de vanguarda com algumas manifestações anteriores. Além da Antropofagia de Oswald de Andrade, separada historicamente por quarenta anos da Tropicália, foram de importância significativa para as realizações tropicalistas: o Cinema Novo, a Bossa Nova, o Concretismo e o Neoconcretismo e o Teatro de Arena. Todas essas manifestações culturais foram incorporadas às informações que vinham de fora do país, como a música dos Beatles, o cinema de Godard e a cultura pop, e assim, misturavam, segundo Ferreira Gullar (apud FAVARETTO, 2007, p. 85), "dados políticos, antropológicos e folclóricos, numa forma exasperante e rica" na tentativa de investigar e questionar criticamente a realidade do país. Esse questionamento abordava "os discursos e as imagens da cultura brasileira, formulados nos termos das oposições reinantes: arte participante e arte alienada, nacional e estrangeiro, arte popular e arte de massa" (FAVARETTO, 2007, p. 84).

Vários autores, nas décadas de cinquenta e sessenta, reatualizaram a potência crítica e criativa de Oswald de Andrade a fim de propor uma caracterização para a cultura brasileira. Hélio Oiticica e José Celso Martinez, por exemplo, o fizeram em textos combativos do final da década de sessenta. Enquanto para Oiticica "a Antropofagia seria a defesa que possuímos contra tal domínio exterior [...], o que não impediu de todo uma espécie de colonialismo cultural, que de modo objetivo queremos hoje abolir, absorvendo-o definitivamente numa Super-antropofagia" (OITICICA, 1967b, p.155), José Celso asseguraria que "Oswald é a possibilidade de uma cultura crítica [...]. É a devoração antropofágica de todos os mitos criados 
para impedir este país de copular com a sua realidade e inventar sua história" (CORRÊA, 1968, p. 122), ou ainda que "ele (Oswald de Andrade) descobre uma forma de expressão totalmente brasileira, um 'pop' brasileiro, quando ainda não se falava em 'pop'” (CORRÊA, 1968, p. 123). O Tropicalismo pretendia assimilar antropofagicamente a "totalidade da realidade cultural brasileira com o fim de desencadear um processo de transformação radical" (BASUALDO, 2007, p. 15). A Antropofagia substitui, seja em Oiticica, Caetano ou José Celso, a racionalidade de um nacionalismo caracteristicamente militar e purista, e o obstáculo de constituição de uma realidade significativamente brasileira.

A "Super-antropofagia" a que se refere Hélio Oiticica, parte, claramente, do entendimento do modernismo brasileiro, em especial das ideias de Oswald de Andrade: rejeita uma "identidade nacional" que não levasse em conta a verdadeira realidade do país, tendendo a lançar mão de uma representação brasileira exótica e folclórica.

O não levar em conta a verdadeira realidade do país tinha a ver com a ausência de percepção da sociedade diante da possibilidade do novo-riquismo da classe média, que dentro dos seus fuscas zero quilometro empolgava-se com anúncios do tipo "Encoste para a direita, aí vem um Fuscão", ou com frases de efeito como "Pra frente Brasil", "Ninguém segura este país", "Este é um país que vai pra frente". Se de um lado buscava-se a elevação da moral da população pela propaganda institucional, de outro aconteciam torturas e mortes nos porões da ditadura, e as manifestações e sequestros praticados pelas guerrilhas. A criação de uma esfera positiva que envolvesse a população brasileira pedia a existência de uma grande rede de telecomunicações, então, a Rede Globo foi inaugurada em 26 de abril de 1965, transformando-se em modelo ideológico do regime militar. A rede televisiva reforçava a propaganda oficial lançando slogans como "Você constrói o Brasil" e "Brasil, conte comigo!”. As novelas também possuíam temáticas notadamente nacionais, onde os protagonistas representavam cidadãos brasileiros comuns e inseridos em um cenário de modernização. Véu da Noiva, por exemplo, exibida de novembro de 1969 a julho de 1970, era apresentada em sua propaganda como uma novela-verdade, e mostrava em seu enredo a grandeza e a modernidade do Brasil. A rejeição da ordem ditatorial limitava-se, ao menos nos primeiros anos de militarismo, a uma pequena parcela da sociedade, a maioria 
absoluta estava integrada à normalidade e cantava: "Eu te amo, meu Brasil, eu te amo".

As ideias nacionalistas que ganhavam popularidade na década de sessenta inclinavam-se para uma "busca obsessiva pela pureza e à rejeição de informações estrangeiras" (NAVES; COELHO, 2007, p. 200). A redescoberta de Oswald de Andrade e a releitura do Manifesto Antropófago permitiram que o grupo de artistas e intelectuais que formava a geração tropicalista alterasse, ou ao menos tentasse, tais ideais. Com a ênfase ao nacionalismo de um lado, e a importação cultural de outro, "a ideia de devoração foi reapresentada como forma de relativização dessas posições” (FAVARETTO, 1979, p. 34).

No texto "Tropicalismo, antropologia, mito, ideograma", Glauber Rocha considera o movimento moderno de 1922 como o "início de uma revolução cultural no Brasil” (ROCHA, 1969, p. 150); Glauber entende a Antropofagia como a devoração, por parte de Oswald de Andrade, de toda a cultura colonial. Para o cineasta, os termos Antropofagia e Tropicalismo tornam-se sinônimos, "a antropofagia (ou o tropicalismo, também chamado assim)" (ROCHA, 1969, p. 150) possibilitaram a abertura de todas as representações culturais e, por sua vez, constituem a importância maior da cultura brasileira. Para Glauber Rocha, ambos presentificam a consciência do subdesenvolvimento do país, "tropicalismo é a aceitação, ascensão do subdesenvolvimento", assim como, a consciência de uma "cultura colonial que não é a rejeição à cultura ocidental", da cultura importada poderíamos aceitar tudo, "aceitamos a ricezione [recepção] integral” (ROCHA, 1969, p. 151). Foi através desta aceitação e da sua relação com todas as linguagens artísticas que se dá a procura de uma nova estética.

"Só me interessa o que não é meu. Lei do homem. Lei do antropófago" (ANDRADE, 1928, p. 13), afirma Oswald de Andrade em seu manifesto. O Tropicalismo se apropria deste lema para estabelecer as bases de uma transformação cultural, porém, a devoração do que não é "nosso" não se dá como cópia, mas como uma fusão, como uma apropriação, uma espécie de hibridismo. A Antropofagia oswaldiana olha a cultura primitiva para criar, mas também questionar a cultura ocidental. Se o modernismo europeu buscou o novo em pleno ambiente urbano, com a Revolução Industrial praticamente instalada na sociedade, o modernismo de Oswald prefere se referenciar nas culturas africana e indígena, ora aproximando-se, ora afastando-se da vanguarda européia. No pensamento antropofágico, os elementos autóctones brasileiros, tornam- 
-se princípios de revolta, de revolução, de transformação e de contravenção.

Ao contrário do que acontece na Europa e na América do Norte, tínhamos a necessidade de caracterizar nossa cultura pelo fato de não possuirmos uma tradição pictórica. Segundo Oiticica (1967b, p. 155), é nesse aspecto que "nos diferenciamos do europeu com seu peso cultural milenar e [d]o americano do norte com suas solicitações superprodutivas. Ambos exportam suas culturas de modo compulsivo, necessitam mesmo que isso se dê, pois o peso das mesmas as faz transbordar compulsivamente".

Frederico Morais também aborda a questão da ausência da tradição pictórica do Brasil em seu artigo - "Por que a vanguarda brasileira é carioca" - apresentado no Seminário "Propostas 66 " 4 , onde considera o Barroco mineiro uma redução de valores primitivos a termos nacionais, logo, uma característica imanente da vocação antropofágica. "Sem raízes nacionais, já começamos com uma arte verdadeiramente moderna e anticlássica, como o barroco, até hoje nossa manifestação mais autenticamente nacional. Daí sermos vocacionalmente modernos" (MORAIS, 1966, p. 33). Continuando seu raciocínio, Morais estabelece três pontos fundamentais como base da arte de vanguarda: o Barroco, a vocação construtiva e a Antropofagia, que, por sua vez, iriam refletir na produção crítica e artística brasileira da segunda metade da década de sessenta. A vocação construtiva é dada, segundo o crítico, no geometrismo moderno, através de Alfredo Volpi (1896-1988) e Tarsila do Amaral (1886-1973), na arquitetura de Niemeyer e nos movimentos concreto e neoconcreto.

A Antropofagia oswaldiana coloca os índios que habitavam as terras brasileiras, na ocasião da chegada dos portugueses, como devoradores de seus inimigos, entre eles os próprios colonizadores. Em seu manifesto, o poeta modernista, procura recuperar a essência do caráter primitivo: o canibalismo, o ócio e o conhecimento mítico, "[...] nunca tivemos gramática, nem coleções de velhos vegetais. E nunca soubemos o que era urbano, suburbano, fronteiriço e continental. Preguiçosos no mapa-múndi do Brasil”. Ao longo do Manifesto Antropófago, Oswald de Andrade aborda a necessidade de rever as questões lusocêntricas que regem o país e que desprezam a especificidade brasileira - "Antes dos portugueses descobrirem o Brasil, o Brasil tinha descoberto a felicidade". "Queremos a

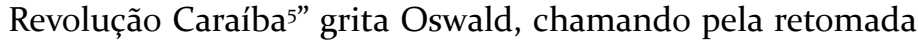
ideológica da cultura primitiva. Sem a "revolução" o povo bra- 
sileiro continuaria no papel de fantoche manipulado pelos colonizadores: "O índio vestido de senador do Império. [...]. Ou figurando nas óperas de Alencar cheio de bons sentimentos portugueses", nesta frase Oswald refere-se ao romance indianista O Guarani (1857) de José de Alencar (1829-1877), em que o herói indígena Peri possui atitudes inscritas na conformidade da corte portuguesa.

\section{A vocação antropofágica}

A inauguração da era antropofágica é fixada por Oswald de Andrade no ano de 1556, quando os índios Caetés devoram o primeiro bispo do Brasil, o padre Dom Pero Fernandes Sardinha - mais conhecido por Bispo Sardinha - após ter naufragado no litoral de Alagoas; ao assinar o manifesto, Oswald o faz da seguinte maneira: "Oswald de Andrade / Em Piratininga ${ }^{6}$ / Ano 374 da Deglutição do Bispo Sardinha”" O ato de deglutição dos índios Caetés não implica em saciar a fome, mas em um ritual de incorporação dos atributos do "outro" (exterior), superando as limitações do "eu" (interior) através da assimilação e do acréscimo das qualidades do inimigo.

A vocação antropofágica verificada no povo primitivo apresenta, no modernismo brasileiro, um semblante ideológico na tentativa de resolver a questão da dependência cultural dos centros europeus na década de vinte. A Antropofagia de Oswald de Andrade propõe a apreensão dos modelos estrangeiros a fim de evitar o refúgio da produção artístico-cultural brasileira aos temas locais de tendência nacionalista. Quando Oswald chama a "revolução Caraíba" "contra as elites vegetais. Em comunicação com o solo", ele está se referindo a uma produção cultural que não apreende, mas copia modelos europeus, e assim, despreza o sentimento de "brasilidade"; a cópia vegetativa de modelos torna-se incapaz de percepção crítica, fator que promove as atitudes significativas para a formação de uma cultura.

Quando a vanguarda brasileira da década de sessenta pensa em uma especificidade cultural para o país, não propõe, de forma alguma, uma prática artística limitada ao Brasil, mas sim, uma arte favorecida pelo sentimento de "brasilidade", como anunciado no Modernismo. Esse ideário de "brasilidade" modernista busca uma identidade cultural dotada de um caráter universal, significando a superação da superficialidade da cultura brasileira, assim como, sua aceitação, por meio de singularidades e individualidades, no discurso artístico promovido pelos países 
hegemônicos. Mário de Andrade (1925, p. 218) afirmava que "só sendo brasileiros isto é adquirindo uma personalidade racial e patriótica (sentido físico) brasileira que nos universalizaremos, pois que então concorreremos com um contingente novo, novo assemblage de caracteres psíquicos para o enriquecimento do universal humano". É também com este sentimento de "brasilidade" que Oswald de Andrade propõe que se olhe para a cultura primitiva sem, contudo, cair na armadilha dos nacionalismos. Oswald de Andrade pensava na Antropofagia como um ritual capaz de transformar o negativo em positivo, ou seja, deglutir as informações exteriores juntamente com o primitivismo nativo seria uma estratégia de emancipação cultural, foi essa a concepção retomada pelos tropicalistas.

A reinvenção da expressão estrangeira dentro de um contexto brasileiro dilui as oposições tradicionais que envolvem um discurso de identidade cultural: nacional e estrangeiro, arcaico e moderno, bárbaro e civilizado, transgressão e ordem, entre outros. Celso Favaretto (1979, p. 37) afirma que no Tropicalismo "as contradições culturais são expostas pela justaposição do arcaico e do moderno, segundo um tratamento artístico que faz [...] ressaltar os recalques sociais e o sincretismo cultural, montando uma cena fantasmagórica toda feita de cacos". Esta justaposição entre arcaico e moderno a que se refere Favaretto, resultaria no "cafonismo", que por sua vez, seria característica específica do comportamento estético-tropicalista, exacerbando o mau gosto como conduta típica do subdesenvolvimento. A Antropofagia serviu de ponto de partida para as discussões do Tropicalismo através da ironia de uma realidade nacional. Os tropicalistas libertaram a arte de preconceitos nacionalistas conferindo-lhe uma postura experimental. A ligação entre os tropicalistas e Oswald de Andrade se deu de forma intuitiva: tanto a Tropicália de Caetano Veloso, quanto a Tropicália de Hélio Oiticica, por exemplo, simbolizam um país contraditório, aproximando o arcaico e o moderno, o local e o universal. Com o teatro a relação se deu de forma mais direta com a encenação de O Rei da Vela, porque, ao dirigir a peça com uma comicidade exagerada, José Celso, além de realçar e debochar da postura burguesa, apresentava uma compreensão lasciva da política e uma linguagem não linear.

Foi através da absorção de manifestações, que a princípio poderiam parecer incompatíveis às práticas artísticas brasileiras, que se inicia o estabelecimento de uma linguagem típica, complexa e universal para a cultura do país. Esta situação pode ser exemplificada com a necessidade dos músicos tropicalistas de utilizarem "guitarras, amplificadores, conjunto e principalmente a roupa- 
gem" (OITICICA, 1968a) teatral. Era a necessidade de uma manifestação ambiental no cenário artístico cultural do país. Essa manifestação ambiental decorreu de todas as rupturas propostas desde a época do Concretismo e se tornou a prática artística que Oiticica passaria a defender e a realizar após a Tropicália.

Muitos autores consideram a Semana de 22 como a primeira tentativa de criação de uma arte efetivamente brasileira. Este movimento procurou retirar do país a ideia de possuirmos uma cultura moldada pelos colonizadores e referenciada na dominação estrangeira. O Modernismo brasileiro fez um movimento simultâneo de olhar para o exterior e valorizar temáticas regionalistas. Reunidos em torno de Oswald de Andrade a geração modernista dedicou-se a fazer uma autocrítica dos valores que constituíam sua própria cultura. Ainda que cautelosamente, o Brasil da década de vinte procurava romper com as práticas culturais dos tempos de colônia. É assim que Mário de Andrade (1893-1945), mesmo já afirmando a existência de uma cultura brasileira moderna, volta-se para as representações primitivas. Na Europa, a arte moderna reagia contra o ideário naturalista tradicional da cultura ocidental admitindo a expressão plástica da produção artística de povos primitivos; esse gosto pela arte primitiva do modernista europeu equiparava-se com o ideário universalista e a tendência pela cultura folclórica e popular de Mário de Andrade, que, por sua vez, elege "as manifestações culturais, populares, coletivas, rurais e anônimas como base para a criação de uma cultura moderna erudita no país" (WISNIK, 2004). Pedrosa (1952, p. 128-129) acredita que o Brasil de Mário de Andrade "é antes um motivo [...], do que uma abstração ideológica, convencional e cívica e fria". Foi através do compartilhamento desta sentença que os modernistas redescobriram a vernaculidade brasileira. Ao contrário dos europeus que precisavam recorrer à África e à Oceania para se familiarizarem com a cultura primitiva, os modernistas brasileiros tiveram apenas que se voltarem para o interior do país, região que fornecia aos artistas e intelectuais, por meio de um primitivismo físico, uma qualidade instintiva.

A arte moderna se formou, com efeito, quando as correntes imperialistas se espalharam pelo mundo, descobriram os continentes desconhecidos ou ainda não explorados [...], da África, da América, da Ásia ou da Oceania, trazendo consigo uma série de descobertas, entre as quais os fetiches negros, os monstros sul-americanos, arquétipos de outros céus e outros produtos estranhos que [...] naturalistas ou an- 
tropólogos não tiveram coragem de, ao depará-los, elevá-los à categoria de arte (PEDROSA, 1978, p. 342).

Será possível identificar semelhanças no uso do conceito de Antropofagia entre modernistas de 22 e tropicalistas dos anos sessenta? Quais seriam os ideários em comum? O Tropicalismo dos anos sessenta, através da prática da vivência do desejo antropofágico preconizada pelo modernismo oswaldiano, parece ter sido a primeira admissão efetiva das ideias do poeta. O mito da retomada do Brasil primitivo, que foi por décadas questão de resistência cultural, ganha no Tropicalismo condições de existência em um cenário artístico que de intimista passa a ser excessivo. Uma doce barbárie de um projeto cultural coletivo que, através da sua internacionalização, devolve ao exterior aquilo que foi devorado. O Tropicalismo antropofágico conservou aos menos três elementos do estilo oswaldiano: a unificação de doutrinas diversas, o humor pervertido e a atitude anárquica diante dos valores dominantes; assim propôs a mudança de sensibilidade das formas de compreensão e recepção artísticas. O Tropicalismo insere em sua ordem do dia o experimentalismo vigente com os modernistas agora em prol da ruptura cultural.

Por mais que o Tropicalismo tenha colocado em voga as ideias da teoria antropofágica, é preciso evitar o erro de reduzi-lo a uma simples retomada do pensamento de Oswald de Andrade, o momento tropicalista é dotado de particularidades. A originalidade nativa e o fascínio da cultura européia dos modernistas de 22 deslocam-se nos anos sessenta para o "debate sobre a indústria cultural, transferindo-se o enfoque dos aspectos étnicos para os político-econômicos" (FAVARETTO, 1979, p. 38). A Tropicália da década de sessenta inicia o banquete proposto por Oswald, mas coloca à mesa, além da cultura primitiva, a cultura popular.

quis eu com Tropicália criar o mito da miscigenação - somos negros, índios, brancos, tudo ao mesmo tempo [...]. Para a criação de uma verdadeira cultura brasileira, característica e forte, expressiva ao mesmo tempo, essa herança maldita européia e americana terá de ser absorvida, antropofagicamente, pela negra e índia da nossa terra. (OITICICA, 1968c, p. 108)

Para Hélio Oiticica somente através da Antropofagia haveria a assimilação de culturas estrangeiras sem o esvaziamen- 
to da cultura do país. É recuperando as questões do projeto modernista que os tropicalistas da década de sessenta encerram o modernismo brasileiro. Nas palavras de Mário Pedrosa, seguem para a era pós-moderna.

\section{Referências bibliográficas}

AGUILAR, Gonzalo. Na selva branca: o diálogo velado entre Hélio Oiticica e Augusto e Haroldo de Campos. In: BRAGA, Paula (org.). Fios Soltos: a arte de Hélio Oiticica. São Paulo: Perspectiva, 2008. (p. 237-249)

ANDRADE, Mário de. Carta à Manuel Bandeira. 1925. In: MORAES, Marcos Antonio (org.). Correspondência Mário de Andrade e Manuel Bandeira. São Paulo: Editora da Universidade de São Paulo: Instituto de Estudos Brasileiros, Universidade de São Paulo, 2a . Edição, 2001. (p. 217-218)

ANDRADE, Oswald. Manifesto da Poesia Pau-Brasil. 1924. In: Obras completas VI: Do Pau-Brasil à Antropofagia e às Utopias - Manifestos, teses de concursos e ensaios. Rio de Janeiro: Civilização Brasileira, 1970. (p. 3-10)

ANDRADE, Oswald. Manifesto Antropófago. 1928. In: Obras completas VI: Do Pau-Brasil à Antropofagia e às Utopias Manifestos, teses de concursos e ensaios. Rio de Janeiro: Civilização Brasileira, 1970. (p. 13-19)

BASUALDO, Carlos. Tropicália: uma revolução na cultura brasileira (1967-1972). São Paulo: Cosac Naify, 2007.

BRITO, Ronaldo. Neoconcretismo. São Paulo: Cosac \& Naify, 1999.

CAMPOS, Haroldo de (et ali). Plano-piloto para poesia concreta. 1958. In: CAMPOS, Augusto de; PIGNATARI, Décio; CAMPOS, Haroldo. Teoria da poesia concreta: textos críticos e manifestos 1950-196o. Cotia, SP: Ateliê Editorial, 2006. (p. 215-8)

CAMPOS, Haroldo. A poesia concreta e a realidade nacional 1962. In: Arte em Revista - Ano 1 - Número 1. ARANTES, Otília Beatriz Fiori (et ali) (coord.). São Paulo, 1979, Centro de Estudos de Arte Contemporânea. (p. 27-31)

CAMPOS, Haroldo. A arte no horizonte do provável. São Paulo: Editora Perspectiva, 1972.

CAMPOS, Haroldo. Asa delta para o êxtase. Depoimento a Leonora de Barros. 1987. In: Hélio Oiticica. Catálogo da exposição itinerante 1992 - 1997. Roterdã: Witte de With Center for Contemporary Art; Paris: Galerie Nationale du Jeu de Paume; Barcelona: Fundació Antoni Tàpies ; Lisboa : Cen- 
tro de Arte Moderna da Fundação Calouste Gulbenkian; Minneapolis: Walker Art Center; Rio de Janeiro: Centro de Arte Hélio Oiticica. (p. 217-221)

CORDEIRO, Waldemar (et ali). Grupo Ruptura. 1952. In: CONTINENTE SUL SUR. Revista do Instituto Estadual do Livro. No. o6 - 1997. Arte latino-americana: Manifestos, documentos e textos de época. I Bienal do Mercosul. Porto Alegre, 1997, Instituto Estadual do Livro. (p. 103-105)

CORRÊA, José Celso Martinez. A guinada de José Celso. Entrevista a Tite de Lemos. 1968. In: Revista Civilização Brasileira. ANO IV - Caderno Especial n ${ }^{\circ} .2$ - Julho, 1968. Rio de Janeiro: Editora Civilização Brasileira. (p. 115-129)

FAVARETTO, Celso F. Tropicália - Alegoria, alegria. São Paulo: Kairós, 1979.

FAVARETTO, Celso. A invenção de Hélio Oiticica. São Paulo: Editora da Universidade de São Paulo, 2000.

FAVARETTO, Celso. Tropicália: a explosão do óbvio. 2007. In: BASUALDO, Carlos. Tropicália: uma revolução na cultura brasileira (1967-1972). São Paulo: Cosac Naify, 2007. (p. 8196)

GULLAR, Ferreira. Teoria do não-objeto. 1959a. In: Experiência neoconcreta: momento-limite da arte. São Paulo: Cosac Naify, 2007. (p. 90-100)

GULLAR, Ferreira. Manifesto neoconcreto. 1959b. In: Experiência neoconcreta: momento-limite da arte. São Paulo: Cosac Naify, 2007. (Encarte - Fac-símile do catálogo da I Exposição Neoconcreta)

GULLAR, Ferreira. Etapas da arte contemporânea: Do cubismo à arte neoconcreta. Rio de Janeiro: Revan, 1999.

GULLAR, Ferreira. Experiência neoconcreta: momento-limite da arte. São Paulo: Cosac Naify, 2007.

LAGNADO, Lisette. Hélio Oiticica: o mapa do Programa Ambiental. (2 volumes). Tese de doutoramento apresentada ao Programa de Pós-graduação em Filosofia do Departamento de Filosofia da Faculdade de Filosofia, Letras e Ciências Humanas da Universidade de São Paulo (FFLCH/USP), São Paulo, 2003.

MORAIS, Frederico. Por que a vanguarda brasileira é carioca. Tese apresentada em Proposta 66 - Tema: Situação da vanguarda no Brasil. 1966. In: Arte em Revista - ano 1 - $\mathrm{n}^{\circ} 2$. Centro de Estudos de Arte Contemporânea: Maio-Agosto de 1979. (p. 33-34)

NAVES, Santuza Cambraia; COELHO, Frederico Oliveira. Fontes e leituras do tropicalismo - Introdução. 2007. In: 
BASUALDO, Carlos. Tropicália: uma revolução na cultura brasileira (1967-1972). São Paulo: Cosac Naify, 2007. (p. 195203)

NUNES, Benedito. Oswald Canibal. São Paulo: Editora Perspectiva, 1979.

OITICICA, Hélio. Inter relação das artes. s.d. Programa Hélio Oiticica, Tombo: oo37/61. LAGNADO, Lisette (ed.). São Paulo: Itaú Cultural.

OITICICA, Hélio. A busca do supra-sensorial. 1967a. Programa Hélio Oiticica, Tombo: 0192/67 - 8/9. LAGNADO, Lisette (ed.). São Paulo: Itaú Cultural.

OITICICA, Hélio. Esquema Geral da Nova Objetividade. 1967b. In: COTRIM, Cecília; FERREIRA, Glória. Escritos de Artistas: anos 6o e 7o. Rio de Janeiro: Jorge Zahar, 2006. (p. 154-168)

OITICICA, Hélio. A Trama da Terra que Treme (O sentido de vanguarda do grupo baiano). 1968a. Programa Hélio Oiticica, Tombo: 028o/68. LAGNADO, Lisette (ed.). São Paulo: Itaú Cultural.

OITICICA, Hélio. Música popular brasileira (atribuído). 1968b. Programa Hélio Oiticica, Tombo: 0135/68. LAGNADO, Lisette (ed.). São Paulo: Itaú Cultural.

OITICICA, Hélio. Sem título. 1968c. In: Aspiro ao grande labirinto. Rio de Janeiro: Rocco, 1986. (p. 106-109)

OITICICA, Hélio. Brasil Diarréia. 1970. In: Arte em Revista Ano 3 Número 5. FAVARETTO, Celso Fernando; ADDEO, Walter Cezar; MOSTAÇO, Edélcio (organizadores). São Paulo: Centro de Estudos de Arte Contemporânea, 1981. (p. 43-45)

PEDROSA, Mário. Semana de arte moderna. 1952. In: Dimensões da Arte. Rio de Janeiro: Ministério da Educação e Cultura - Departamento de Imprensa Nacional, 1964. (p. 127-142)

PEDROSA, Mário. Arte ambiental, arte pós-moderna, Hélio Oiticica. 1965. In: OITICICA, Hélio. Aspiro ao Grande Labirinto. Rio de Janeiro: Rocco, 1986. (p. 9-13)

PEDROSA, Mário. Opinião... Opinião... Opinião. 1966a. In: Catálogo Opinião 65 - 30 anos. Curadoria de Wilson Coutinho e Cristina Aragão. Rio de Janeiro: Centro Cultural Banco do Brasil, 1995.

PEDROSA, Mário. Crise do condicionamento artístico. 1966b. In: Política das Artes. São Paulo: Editora da Universidade de São Paulo, 1995. (p. 117-123)

PEDROSA, Mário. Variações sem tema ou a arte de retaguar- 
da. 1978. In: Política das Artes. São Paulo: Editora da Universidade de São Paulo, 1995. (p. 341-347)

ROCHA, Glauber. Tropicalismo, antropologia, mito, ideograma. 1969. In: Revolução do Cinema Novo. São Paulo: Cosac Naify, 2004. (p. 150-154)

WISNIK, Guilherme. Plástica e anonimato: modernidade e tradição em Lucio Costa e Mário de Andrade. 2004. Disponível em: http://www.scielo.br/scielo.php?pid=So101-33002007000300009\&script=sci_arttext. Acesso em: 19/05/2010.

ZILIO, Carlos. Da antropofagia à tropicália. In: ZILIO, Carlos; LAFETÁ, João Luiz. O nacional e o popular na cultura brasileira - Artes Plásticas e Literatura. São Paulo: Editora Brasiliense, 1982. (p. 11-56)

\section{NOTAS}

1. O Manifesto Neoconcreto foi publicado pela primeira vez no Suplemento Dominical do Jornal do Brasil no dia 23 de março de 1959, assinado por Ferreira Gullar, Reinaldo Jardim, Theon Spanudis, Amílcar de Castro, Franz Weismann, Lygia Clark e Lygia Pape. No entanto, Ferreira Gullar afirma em 2007 que elaborou o texto do manifesto sozinho, e que sem qualquer modificação recebeu a concordância e a assinatura de todo o grupo.

2. Mário Pedrosa (1901-1981) chamou de arte pós-moderna a arte realizada diante das novas questões do mercado. No pós-modernismo, o problema formal da arte daria espaço a busca da autonomia diante de acontecimentos de qualquer ordem, artísticos ou não. Tomando como base a arte brasileira da década de 196o, Mário Pedrosa $(1965$, p. 9) afirma que o país não participaria da condição pós-moderna "como modesto seguidor, mas como precursor".

3. O Grupo Noigandres foi formado em $1952 \mathrm{em}$ São Paulo, dando início à poesia concreta no Brasil. O grupo integrava poetas como Augusto e Haroldo de Campos, Décio Pignatari, Ronaldo Azeredo, José Lino Grünewald e Edgar Braga.

4. O ano de 1965 foi, segundo Mário Pedrosa (1966a), um ano de "criatividade coletiva" para as artes plásticas do país. Foram iniciativas como as exposições "Opinião" e "Propostas" que fizeram com que artistas e críticos rompessem com o ostracismo que era verificado na arte brasileira desde o fim do Neoconcretismo, foram estas iniciativas que culminaram em manifestações como a "Declaração de Princípios Básicos de Vanguarda" e a mostra "Nova Objetividade Brasileira". A exposição "Opinião 65" apresentou uma intenção de denúncia, e neste mesmo sentido foram apresentadas as manifestações coletivas "Propostas 65", com exposição e debates, e "Opinião 66". Em dezembro de 1966 acorreu uma série de seminários sobre os aspectos da vanguarda brasileira, ao que foi chamado de "Propostas 66", dos seminários participaram artistas, arquitetos, críticos e sociólogos.

5. O termo Caraíba designa, na língua indígena, uma das primeiras comunidades a tomar contato com os portugueses e que era estabelecida no norte do país, como também a língua falada por várias tribos localizadas ao sul.

6. Piratininga na língua indígena nomeia a região onde posteriormente surgiu a cidade de São Paulo. 
7. $\mathrm{O}$ ano de 1928, em que foi escrito o manifesto, marca, na verdade, o ano 372 do ato de canibalismo praticado pelos índios Caetés, não se sabe se Oswald apenas se equivocou ao datar o texto como sendo o ano 374 ou se teve algum motivo para isso.

Recebido em: 12/07/10

Aceito em: 03/11/10 
JHANAINNA SILVA PEREIRA JEZZINI

bagdad@onda.com.br

É mestranda em Artes Visuais pela Faculdade Santa Marcelina - FASM.

São Paulo - SP. Brasil. Bolsista pelo PROSUP. Especialista em História da Arte Moderna e Contemporânea e graduada em Licenciatura em Desenho, ambas pela Escola de Música e Belas Artes do Paraná - EMBAP. Integrante do grupo de pesquisa "Hélio Oiticica e a Arte Ambiental", coordenado pela Prof ${ }^{\mathrm{a}}$ Dra Lisette Lagnado. 